Fetal Diagnosis

and Therapy
Fetal Diagn Ther 2008;24:483-490

DOI: $\underline{10.1159 / 000178759}$
Received: July 16, 2007

Accepted after revision: December 5, 2007

Published online: December 1, 2008

\title{
Prenatal Diagnosis of Annular Pancreas: Reliability of the Double Bubble Sign with Periduodenal Hyperechogenic Band
}

\author{
Robert Dankovcik $^{a, b}$ Jan E. Jirasek ${ }^{c}$ Eduard Kucera ${ }^{c}$ Jaroslav Feyereis ${ }^{c}$ \\ Jozef Radonak $^{\mathrm{b}}$ Marek Dudas ${ }^{\mathrm{a}, \mathrm{d}}$

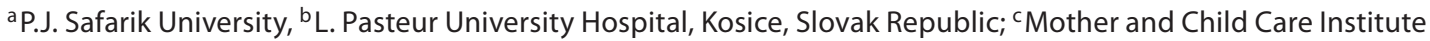 \\ Praha-Podoli, Prague, Czech Republic; ${ }^{d}$ Surgical Research, Developmental Biology Program, Childrens Hospital \\ Los Angeles, Los Angeles, Calif., USA
}

\section{Key Words}

Annular pancreas $\cdot 2-\mathrm{D}$ ultrasound $\cdot$ Prenatal diagnosis $\cdot$

Double bubble $\cdot$ Hyperechogenic band $\cdot$ Differential diagnosis

\begin{abstract}
Objective: To evaluate the power of prenatal 2-D ultrasound examination in the 2 nd trimester as a method of choice for accurate diagnosis of annular pancreas. Methods: Co-incidence of the double bubble sign (often accompanying gastroduodenal dilatation) together with a hyperechogenic band around the duodenum (corresponding with the tissue of annular pancreas) was used as a diagnostic criterion. Findings from postnatal surgery served for verification. Results: From 7,897 screened pregnancies, annular pancreas was proven in the cases where both signs were present, but never without the hyperechogenic band $\left(\mathrm{N}_{1}=3, \mathrm{~N}_{2}=3, \mathrm{p} \leq\right.$ 0.05). Sensitivity and specificity were $100 \%$. Conclusions: More multicentric studies are required to test this approach. The following diagnostic strategy is reasonable at the present time: when the double bubble sign is discovered, always suspect annular pancreas and look for the second sign: hyperechogenic bands around the duodenum. Also look for
\end{abstract}

known associated anomalies, and vice versa, if any of associated anomalies are noted, also search specifically for the signs of annular pancreas.

Copyright $\odot 2008$ S. Karger AG, Basel

\section{Introduction}

The main characteristic feature of annular pancreas (Lat. pancreas anulare; anulus - a ring, anularis - ring shaped) is a band or a ring of pancreatic tissue around the duodenum. This rarely diagnosed congenital disorder results from the pathologically positioned embryonic part of the pancreas $[1,2]$. The tissue of annular pancreas usually spans the descending duodenum close to Vater's papilla, rarely elsewhere [3]. In about a quarter of cases, the duodenum is circled totally, and in about $75 \%$ only partially [4]. This condition may be completely asymptomatic and sometimes the diagnosis is made in adulthood or even at the time of necropsy [5]. However, if the pancreatic ring causes a duodenal constriction, clinical symptoms of annular pancreas may appear immediately after birth. Overall, in the neonatal period, annular pancreas causes about $1 \%$ of intestinal obstructions, and accounts

\section{KARGER}

Fax +41613061234 E-Mail karger@karger.ch www.karger.com
(ㄷ) 2008 S. Karger AG, Basel

1015-3837/08/0244-0483\$24.50/0

Accessible online at:

www.karger.com/fdt
Robert Dankovcik, $\mathrm{MD}, \mathrm{PhD}$

2nd Department of Obstetrics and Gynecology

L. Pasteur University Hospital, Rastislavova 43

SK-04001 Kosice (Slovak Republic)

Tel. +421 905359 381, Fax +421 55615 3219, E-Mail dankovcik@mail.pvt.sk 
Table 1. Cardinal diagnostic signs of annular pancreas (AP) in sonography and their differential diagnosis [21, 23, 39, 43-52]

\begin{tabular}{|c|c|c|}
\hline Key diagnostic signs of AP & Diagnostic value & Differential diagnosis \\
\hline Double bubble sign & $\begin{array}{l}\text { Not pathognomic per se: } \\
\text { 1. AP may or may not cause } \\
\text { duodenal obstruction } \\
\text { 2. Many other conditions can } \\
\text { cause double bubble }\end{array}$ & $\begin{array}{l}\text { Duodenal atresia } \\
\text { Various duodenal obstructions: } \\
\text { - Intrinsic: intraluminal diaphragms/webs, stenosis } \\
\text { - Extrinsic: pyloric atresia, Ladd's band, abdominal masses, } \\
\text { intestinal malrotation, diaphragmatic hernia } \\
\text { Duodenal duplication } \\
\text { Amniotic fold } \\
\text { Distended esophagus } \\
\text { Sandal gap } \\
\text { Upper left abdominal cystic structures: gastric duplication, } \\
\text { splenic cyst, renal cyst, pancreatic cyst } \\
\text { Upper right abdominal cystic structures: choledochal cyst, } \\
\text { hepatic cyst, omental cyst/fold, ovarian cyst, renal cyst }\end{array}$ \\
\hline $\begin{array}{l}\text { Hyperechogenic bands } \\
\text { around the duodenum }\end{array}$ & $\begin{array}{l}\text { Highly pathognomic, but relatively } \\
\text { difficult to see } \\
\text { In conjunction with the double } \\
\text { bubble sign: AP is likely present }\end{array}$ & Currently unknown \\
\hline
\end{tabular}

for less than $5 \%$ of all duodenal obstructions $[6,7]$. More importantly, over $40 \%$ of annular pancreas cases are associated with life-threatening duodenal atresia or obstruction [5]. Thus, if diagnosed prenatally, it represents an important predictor for gastrointestinal emergencies.

Ultrasound diagnosis of a partial or complete duodenal obstruction is almost exclusively based on detection of the so-called double bubble sign, resulting from simultaneous dilatation of the stomach and the duodenum. Based on all known literature records [8-22], prenatal diagnosis of annular pancreas is usually done in those cases that are accompanied with remarkable duodenal obstruction, i.e. when a well-developed double bubble sign is present. However, a similar characteristic double bubble appearance on ultrasound images may also result from several different pathological conditions, such as intestine duplications, tissue bands, and many other [23] (see table 1). In the very best interest of an unborn patient, it is extremely important to differentiate the cause of duodenal impassability before birth, to determine the prognosis, and to prepare for appropriate treatment modalities in the postnatal period. Thus, another annular pancreas-specific diagnostic marker, in addition to the double bubble sign, would be extremely helpful. Similar to our cases presented below, alongside with the double bubble sign, hyperechogenic bands surrounding the duodenum were also observed in verified cases of annular pancreas by several groups $[9,10,17,19,22]$. In further support of these initial and yet statistically nonvalidated findings, we report on 3 new cases of a reliable diagnosis of annular pancreas based on the presence of both signs at the same time. Detailed analysis of a diagnostic value of both signs, either alone or in combination, is provided together with revised and summarized sonographic guidelines and tips for future research.

\section{Methods}

Time Period and Population Size

Between August 1999 and July 2007 (8-year period), 7,897 pregnancies were screened in our prenatal ultrasonography unit. There were no selection criteria applied, and all pregnant women referred to our unit were routinely screened for the presence of any fetal anomalies. Special attention was paid to the duodenal region in all cases, and the double bubble sign and hyperechogenic periduodenal bands were specifically looked for. One pregnant woman with a fetus displaying prenatal signs of annular pancreas that was verified postnatally did not agree with publication of her health-related details. Therefore, this case is just mentioned and included in the total count of positive cases, but could not be described in detail as a full-featured case report.

\section{Evaluation of Sensitivity, Specificity, and Statistical}

Significance

The presence of any of the two scored diagnostic signs (double bubble, hyperechogenic bands) was assigned a value 1; the absence was marked as 0 . In each group of the fetuses with double bubble (with postnatally proven vs. disproved annular pancreas), all marks for prenatal sonographic findings were added up and the resulting values (theoretically ranging from 0 to 2) were used for statistical analysis. The $\mathrm{H}_{1}$ hypothesis was directional, pre- 
Table 2. Distribution of two sonographic signs of annular pancreas in 7,897 fetuses, and a definition of groups with true or false diagnosis for statistical purposes

\begin{tabular}{|c|c|c|c|}
\hline & $\begin{array}{l}\text { Double bubble: no } \\
\text { Hyperechogenic band: no }\end{array}$ & $\begin{array}{l}\text { Double bubble: yes } \\
\text { Hyperechogenic band: no }\end{array}$ & $\begin{array}{l}\text { Double bubble: yes } \\
\text { Hyperechogenic band: yes }\end{array}$ \\
\hline Pancreas anulare surgically proven & no further reference & 0 (false negatives) & 3 (true positives) \\
\hline Pancreas anulare surgically disproved & no further reference & 3 (true negatives) & 0 (false positives) \\
\hline Total fetuses & 7,891 & 3 & 3 \\
\hline
\end{tabular}

dicting that the addition of hyperechogenic bands as a second diagnostic criterion will lead to an accurate diagnosis of annular pancreas; the $\mathrm{H}_{0}$ hypothesis was that there is no discriminatory power of such a diagnostic procedure. Having a very small number of independent unpaired probands, we used both Wilcoxon one-tailed rank-sum test [24] and Peto odds ratio (i.e. the OR corrected for the error caused by zero occurrences of some experimental outcomes in an unmatched case-control study using the null hypothesis) [25]. The diagnostic specificity, i.e. the measure of a power to recognize healthy fetuses as healthy, was calculated according to a conventional formula: SP = (number of true negatives)/(number of true negatives + number of false positives). Sensitivity was defined as SE = (number of true positives)/(number of true positives + number of false negatives).

\section{Examination Conditions}

Pregnant women from the case report section were examined in the usual horizontal position. Fetal ultrasound examination was performed using USG Aloka 5000 with a convex abdominal probe 3.5-5 MHz (case 1) and an Accuvix QX ultrasound machine by Medison with abdominal 2-D/3-D/4-D probe (case 2). In both cases, favorable fetal orientation resulted in no unwanted anechogenic shadows in the duodenal region, and furthermore, a hydramnion present in both cases has promoted excellent hydroacoustic conditions. Positive findings of diagnostic signs were tested for their time stability by repeated examination, observation from different angles, and by continuous monitoring that lasted a few minutes and encompassed active fetal movements.

Human Subjects' Rights and Policies

This study is based exclusively on diagnostic noninvasive observations and standard healthcare surgery. No experiments on human subjects were involved. All healthcare and data collection procedures were in accordance with the ethical standards of the L. Pasteur University Hospital and complied with applicable state laws and regulations. No private, identification, or otherwise sensitive data or patient photographs are used in this article.

\section{Results}

Out of 7,897 screened pregnancies, 6 displayed the double bubble sign. Our aim was to identify which of these obstructions are caused by or associated with annular pancreas. In three of the double bubble-positive pregnancies, also hyperechogenic bands around the duodenum were detected, and the diagnosis of annular pancreas was confirmed during postnatal surgery. Conversely, annular pancreas was not found during postnatal examination of any of the children born from pregnancies with the presence of the double bubble sign but no hyperechogenic bands. No false-positive diagnoses were made, and thus the specificity of the used diagnostic criteria for annular pancreas is equal to $100 \%$ (table 2). The diagnostic sensitivity related to identification of annular pancreas among fetuses with a double bubble with or without hyperechogenic bands was also $100 \%$. To our best knowledge, none of the fetuses with negative findings has displayed annular pancreas after birth, but it was not possible to verify this in the entire examined population (most of the pregnant women with negative findings usually do not come back to our prenatal center and deliver elsewhere without further feedback reference). The statistical significance of diagnostic differences between the group with hyperechogenic bands versus the group without them was detected as marginal (Wilcoxon rank-sum test, $\left.\mathrm{p}_{0} \leq 0.05\right)$. Together with a Peto odds ratio of 28 ( $95 \%$ confidence interval $=1.5$ to infinity), our observations clearly support the correlation between the co-occurrence of both prenatal diagnostic signs with a real postnatal presence of annular pancreas.

Details of two true-positive cases are described below; for the 3rd case, we did not obtain consent to publish medical details.

\section{Case Report 1}

The 1st case was a 26-year-old primigravida with no significant findings in her history. Her triple test was negative - Down syndrome risk 1:980. During the ultrasound examination in the 21st week of pregnancy, the biometric findings corresponded to the gestation age according to the last period as well as to the measurements from a previous ultrasound examination in the 12th week of pregnancy. A normal 3-vessel umbilical cord and hy- 


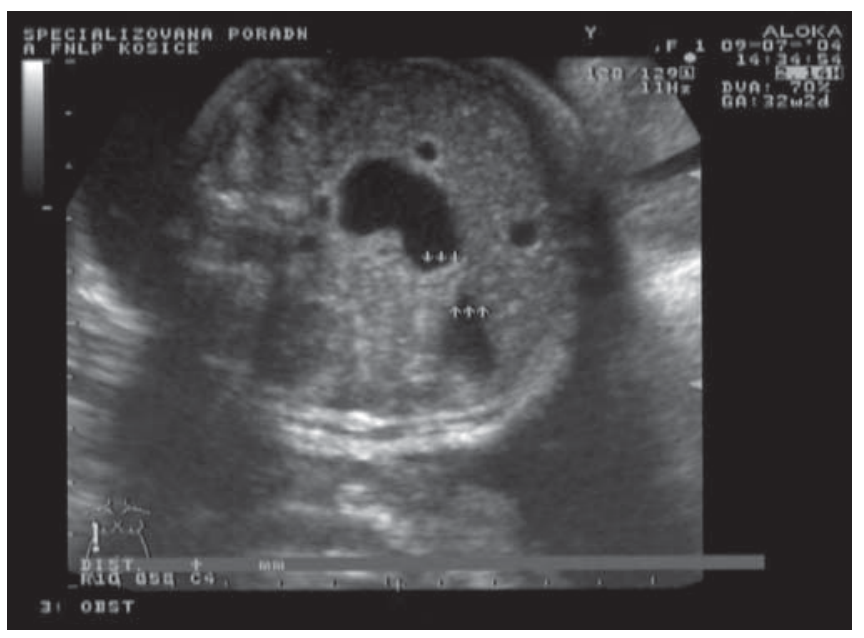

Fig. 1. Ultrasound findings in case 1. Arrows point at hyperechogenic tissue of annular pancreas.

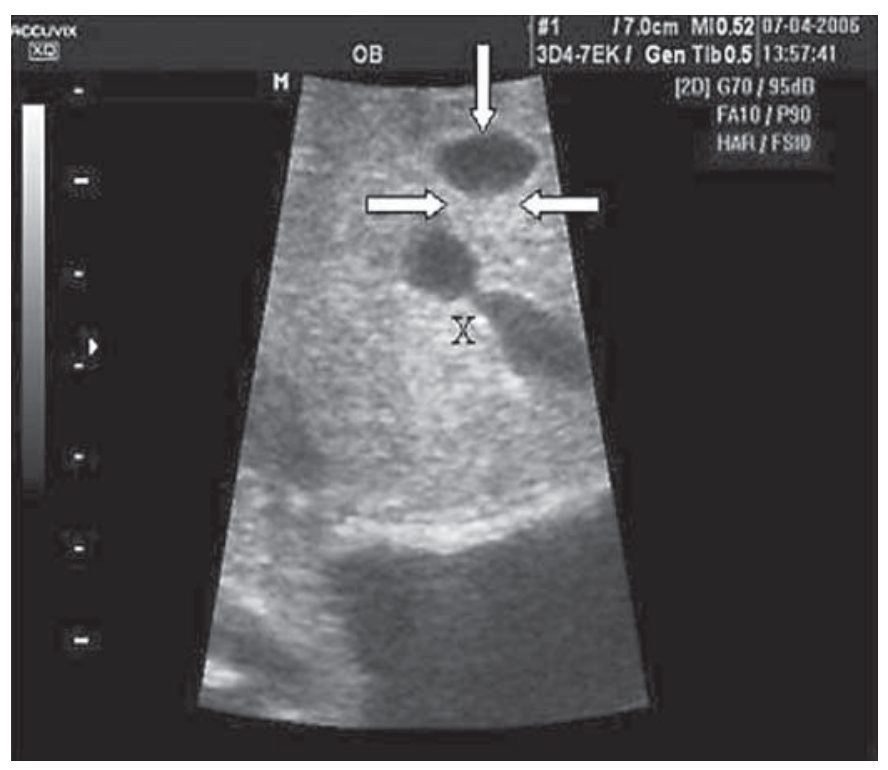

Fig. 2. Ultrasound findings in case 2. White arrows point at hyperechogenic tissue of annular pancreas completely surrounding the middle part of the duodenum. $\mathrm{X}$ indicates stenosis of the duodenum.

dramnion were present. The so-called double bubble sign was noticed in the fetal abdomen (fig. 1). In the duodenal region, a hyperechogenic band $360^{\circ}$ around the duodenum was observed in multiple viewing planes. A sample of the amniotic fluid was submitted for genetic testing.
The karyotype was normal, 46, XX. The child was delivered by standard vaginal delivery in the 39th week of pregnancy. On the 2nd day after the delivery, a laparotomy was performed due to signs of a high gastrointestinal obstruction. A duodenal stenosis by annular pancreas was discovered during the operation. A side-to-side duodeno-duodenal anastomosis was performed. The postoperative course was without complications.

\section{Case Report 2}

A 20 -year-old tercigravida was referred for examination by an ultrasound consultant in the 26th week of pregnancy due to a suspected duodenal atresia. Prenatal biochemical testing was not performed. Fetal biometry findings suggested a lag time of 18 days behind the calculation from the last menstruation period. Fetal morphology - except for the double bubble sign - was normal. Hydramnion grade I was present. In the duodenal region, we observed a massive band of hyperechogenic tissue completely $\left(360^{\circ}\right)$ surrounding the middle part of the duodenum (fig. 2). The child was born in the 36th week of pregnancy by vaginal delivery after a premature rupture of membranes. A laparotomy was performed $52 \mathrm{~h}$ after delivery due to signs of gastrointestinal obstruction. During the operation, a stenosis was discovered in the distal part of the duodenum and the annular pancreas was located proximally, above the stenotic part. The stenotic intestinal segment was removed and the defect was repaired by end-to-end duodeno-duodenal anastomosis. The postoperative course was without complications. Karyotype examination revealed a normal 46, XY constitution.

\section{Discussion}

Discovering annular pancreas as a cause of neonatal or pediatric emergency is a rare incident in any physician's career. With a certain momentum, and with a fairly weak prospectus of acquiring more similar cases for a coherent study, such findings usually become reported as case reports. An inhomogeneous assortment of details was provided in a few known articles of this kind, with a lack of control cases and statistics. Our present study is the first attempt to provide a pilot, small-scale evaluation of the diagnostic usefulness of two known cardinal signs of clinically manifested annular pancreas - the double bubble sign and peripancreatic hyperechogenic bands for prenatal diagnosis. 


\section{Annular Pancreas - A Rare Condition, or Rarely Looked for, or Both?}

Most of the cases of annular pancreas are asymptomatic $[26,27]$, and a systematic screening for this anomaly does not exist in postnatal or prenatal standard practice. Thus, the real incidence of annular pancreas is not known. However, it may be speculated that it is not so important to know the frequency of the defect. Instead, it is extremely important to distinguish cases of intestinal obstruction caused by this disorder in order to plan for appropriate therapeutic interventions after birth. The double bubble sign is a routinely well-known sonographic finding associated with duodenal obstruction of any possible origin. However, from our experience we know that individual practitioners consider the double bubble sign to be a sufficient 'diagnosis' on its own and they never subject to or refer such cases for further differential diagnosis. During the past 8 years, not a single case with a double bubble sign was referred to our unit for diagnostic refinement. Consequently, as the duodenal obstruction becomes clinically manifest after birth, the first diagnosis of annular pancreas is not made during the prenatal period. These facts may contribute to underreporting of this condition, especially in the prenatal period.

\section{Unexpectedly High Occurrence of Annular Pancreas} in Our Study

In our present study, we report 3 cases of annular pancreas found prenatally within a total of 7,897 pregnancies (i.e. occurrence 1:2,632). This is a noticeable difference in comparison with the literature data $(1: 12,000$ to $1: 15,000)$ [28]. The discrepancy can be explained by the fact that our prenatal unit also serves as a countywide reference center, consulting difficult, chromosomally abnormal, and otherwise suspect cases from the entire region of Eastern Slovakia. Although we did not apply any selection criteria to our proband population, the influx of problematic cases referred to us from other centers inherently creates a bias in comparison to a standard pregnant female population. However, our figures may not be as odd as they appear: the largest ever screening for annular pancreas in an adult population has revealed a frequency of 1:1,995 [4], which is much closer to our observation than to the above-mentioned literature data.

\section{The Nature and Diagnostic Relevance of the Double Bubble Sign}

The double bubble sign can be seen on transverse sections of the fetal abdomen. This appearance accompanies duodenal obstruction, and it is the result of a distended
Table 3. Developmental defects that have been found coincident with the diagnosis of annular pancreas [5, 17, 44, 53-62]

$\begin{aligned} 1 & \text { Hydramnion or polyhydramnion } \\ 2 & \text { Down's syndrome (trisomy 21) } \\ 3 & \begin{array}{l}\text { Intestinal malrotations including midgut malrotation and } \\ \text { situs viscerum inversus }\end{array} \\ 4 & \text { Lipomyelomeningocele } \\ 5 & \text { Communicating bronchopulmonary foregut malformation } \\ 6 & \text { Dorsal mesodermal sinus } \\ 7 & \text { Cornelia de Lange syndrome } \\ 8 & \text { Gallbladder agenesis } \\ 9 & \text { CHARGE syndrome } \\ 10 & \text { Myofibromatosis } \\ 11 & \text { Esophageal atresia } \\ 12 & \text { Imperforate anus } \\ 13 & \text { Congenital heart disease } \\ 14 & \text { Chromosomal anomalies } \\ 15 & \text { Meckel's diverticulum } \\ 16 & \text { Polysplenia syndrome }\end{aligned}$

The association strengths and reasons for this co-occurrence are mostly unknown, but it is highly advisable to actively search for annular pancreas in their presence, and analogically, the presence of annular pancreas should be a reason to search for these anomalies.

stomach in the left abdomen and a distended duodenal bulb in the center of the abdomen, just to the right of the midline [23]. The sign is typically observed in the second trimester, although two groups have described the same findings in the first trimester [29-32]. The word 'bubble' has originated from postnatal findings and is actually misleading in the context of prenatal diagnosis; all fetal cavities are in fact filled with fluid, not air. As such, the sonographic appearance of the sign should not change with the probing angle or with the fetal position or movements. Both dilatations are prestenotic. Therefore, communication between the stomach and the duodenum may distinguish duodenal obstructions from other double bubble situations that are caused by dilation of other extraintestinal structures (such as the bile duct, kidneys, etc.; see table 1 for a complete list and source references). Naturally, these structures do not widely communicate with the foregut lumen. All mentioned criteria were met in our present study, which has significantly contributed to a $100 \%$ accuracy of our diagnoses with no false-positive findings. 


\section{Hyperechogenic Periduodenal Bands Are Highly Pathognomic}

All 3 of our cases of annular pancreas were reliably diagnosed on the basis of a simultaneous presence of the double bubble sign and hyperechogenic bands. As it can be logically deduced, these bands represent the pancreatic tissue surrounding the duodenum, and there are barely any structures that could imitate it. The remaining question is whether it is possible to diagnose annular pancreas without manifested duodenal obstruction, i.e. based solely on the presence of hyperechogenic pancreatic tissue around the duodenum without the double bubble sign. Knowledge about such a risk factor would be highly beneficial for those children without manifest antenatal duodenal congestion (and from a purely scientific aspect, also for determining the real incidence of annular pancreas). In our experience, this is not possible, because without the gastroduodenal dilation (and often a remarkable hydramnion) the pancreatic ring is very difficult if not impossible to identify among echogenic intestinal loops.

\section{Applicability of a Two-Sign Diagnosis for Prenatal}

Detection of Annular Pancreas

Nowadays, prenatal diagnosis of annular pancreas is extremely rare - with only a few cases reported [8-22]. However, screening efficacy for this anomaly is usually high due to characteristic findings, well visible even on old equipment of substandard quality. Whereas firm ultrasonographic criteria for annular pancreas cannot be established based on our 3 patients and/or on sporadic literature reports, the co-occurrence of the two typical features - the double bubble sign and hyperechogenic bands - may prove useful for a reliable diagnosis. Based on our observations, and in accordance with studies of others referenced above, a focused examination of the area around the distended gastroduodenum using highresolution ultrasound equipment is recommended in all cases of suspected or proven duodenal obstruction. Detection of a hyperechogenic circular band, complete or incomplete, usually located around the distal part of the duodenum, appears to be a good marker for the diagnosis of annular pancreas. It is highly desirable to increase the number of documented case studies to confirm this relationship. It is equally important to recognize any unrelated causes of duodenal obstruction or nonobstructive causes of the double bubble sign to avoid misdiagnosis (see table 1 for the list of related sonographic features and references).

In addition, since annular pancreas may be associated with multiple severe developmental defects, it is impor- tant to actively search for its presence when some of the usual associated anomalies are detected (such as Down's syndrome or (poly)hydramnion; see table 3 for details and references). And vice versa, for a good quality of prenatal diagnosis, the finding of annular pancreas should be a reason to search for additional developmental anomalies.

\section{Future Research Directions}

Conversely to ultrasonography, early genetic prediction of annular pancreas based on amniocentesis, CVS, or preimplantation testing [33] is currently not feasible due to a lack of specific genetic markers. However, annular pancreas appears to have an autosomal dominant inheritance in many cases [23], and several genetic regulation circuits have been recently identified in pancreatic development and/or in experimental induction of annular pancreas, including the key players such as FGF, TGF- $\beta /$ BMP or Sonic hedgehog growth factors [34-37]. This brings a new promising dimension into prenatal research on pancreatic anomalies and their laboratory diagnostics, though the practical outcomes seem to be quite remote at the present time. Keeping in mind that radiological imaging methods for pancreas [38-42] will most likely remain problematic during prenatal development, improvements in sonographic diagnosis represent the most rational research direction with an immediate impact on clinical practice. Timely and accurate prenatal diagnosis of annular pancreas helps neonatologists with their diagnostic management, and surgeons can search for known associated anomalies and plan ahead for an appropriate timing of the operative treatment $[17,18]$.

\section{Acknowledgements}

This work was in part supported by the grants LPP-0155-06 (APVV, EU), 1/4320/07 (VEGA, EU), and DE018459 (NIH, USA). The clinical part of this study was not extramurally sponsored and resulted exclusively from standard healthcare offered at the L. Pasteur University Hospital.

References

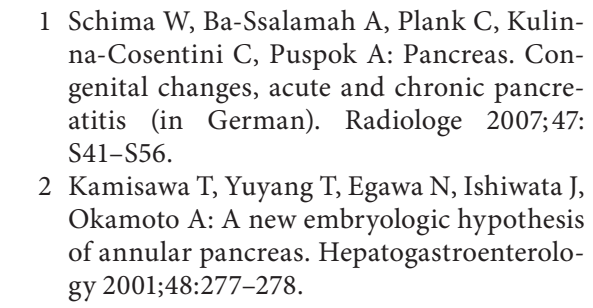

Dankovcik/Jirasek/Kucera/Feyereisl/ Radonak/Dudas 
-3 Rinnab L, Schulz K, Siech M: A rare localization of annular pancreas at the pars horizontalis duodeni - case report (in German). Zentralbl Chir 2004;129:513-516.

-4 Papachristou GI, Topazian MD, Gleeson FC, Levy MJ: EUS features of annular pancreas (with video). Gastrointest Endosc 2007;65: 340-344.

5 Vijayaraghavan SB: Sonography of pancreatic ductal anatomic characteristics in annular pancreas. J Ultrasound Med 2002;21: 1315-1318.

6 Hays DM, Greaney EM Jr, Hill JT: Annular pancreas as a cause of acute neonatal duodenal obstruction. Ann Surg 1961;153:103112.

7 Ravitch MM: The pancreas in infants and children. Surg Clin North Am 1975;55:377385.

-8 Akhtar J, Guiney EJ: Congenital duodenal obstruction. Br J Surg 1992;79:133-135.

9 Boomsma JH, Weemhoff RA, Polman HA: Sonographic appearance of annular pancreas in utero. A case report. Diagn Imaging 1982;51:288-290.

10 Clark JF, Hales E, Ma P, Rosser SB: Duodenal atresia in utero in association with Down's syndrome and annular pancreas. J Natl Med Assoc 1984;76:190-192.

- 11 Fernandez GN, Prieto ES, Ibanez FA, Fernandez CB, Lopez SJ, Fernandez TJ: Deletion 11 q23 $\rightarrow>$ qter (Jacobsen syndrome) associated with duodenal atresia and annular pancreas (in Spanish). An Esp Pediatr 2002;57: 249-252.

12 Gluer S, Petersen C, Ure BM: Simultaneous correction of duodenal atresia due to annular pancreas and malrotation by laparoscopy. Eur J Pediatr Surg 2002;12:423-425.

-13 Grosfeld JL, Rescorla FJ: Duodenal atresia and stenosis: reassessment of treatment and outcome based on antenatal diagnosis, pathologic variance, and long-term followup. World J Surg 1993;17:301-309.

14 Hsu CY, Chiba Y, Fukui O, Sasaki Y, Miyashita S: Counterclockwise barber-pole sign on prenatal three-dimensional power Doppler sonography in a case of duodenal obstruction without intestinal malrotation. J Clin Ultrasound 2004;32:86-90.

-15 Kehrer-Sawatzki H, Daumiller E, MullerNavia J, Kendziorra H, Rossier E, du Bois G, Barbi G: Interstitial deletion del(10)(q25.2q25.3 approximately 26.11) - case report and review of the literature. Prenat Diagn 2005;25:954-959.

16 Lainakis N, Antypas S, Panagidis A, Alexandrou I, Kambouri K, Kyriazis C, Dolatzas T: Annular pancreas in two consecutive siblings: an extremely rare case. Eur J Pediatr Surg 2005;15:364-368.

- 17 Martin-Hirsel A, Cantrell CJ, Hulka F: Antenatal diagnosis of a choledochal cyst and annular pancreas. J Ultrasound Med 2004; 23:315-318
18 Ozturk H, Ozturk H, Gedik S, Duran H, Onen A: A comprehensive analysis of 51 neonates with congenital intestinal atresia. Saudi Med J 2007;28:1050-1054.

19 Pachi A, Maggi E, Giancotti A, Torcia F, de Prosperi V: Ultrasound diagnosis of fetal annular pancreas. J Perinat Med 1989;17:361364.

20 Poki HO, Holland AJ, Pitkin J: Double bubble, double trouble. Pediatr Surg Int 2005;21: 428-431.

21 Sugimoto T, Yamagiwa I, Obata K, Ouchi T, Takahashi R, Suzuki R, Shimazaki Y: Choledochal cyst and duodenal atresia: a rare combination of malformations. Pediatr Surg Int 2004:20:724-726.

22 Weiss H, Sherer DM, Manning FA: Ultrasonography of fetal annular pancreas. Obstet Gynecol 1999;94:852.

23 Imseis HM, Jeanty P: Case of the week \#4 (1999-07-09-05). www.thefetus.net.

24 Mann HB, Whitney DR: On a test whether one of two random variables is stochastically larger than the other. Ann Math Statist 1947; 18:52-54.

25 Fleiss JL: The statistical basis of meta-analysis. Stat Methods Med Res 1993;2:121-145.

26 Hamm M, Rottger P, Fiedler C: Pancreas anulare as a rare differential diagnosis of duodenal stenosis in adulthood (in German). Langenbecks Arch Chir 1997;382:307-310.

27 Desai MB, Mitchell DG, Munoz SJ: Asymptomatic annular pancreas: detection by magnetic resonance imaging. Magn Reson Imaging 1994;12:683-685.

28 Hulvat MC, Kumar RB, Newman BM, Muraskas JK: Annular pancreas in identical twin newborns. J Pediatr Surg 2006;41:e19e21.

29 Tsukerman GL, Krapiva GA, Kirillova IA: First-trimester diagnosis of duodenal stenosis associated with oesophageal atresia. Prenat Diagn 1993;13:371-376.

30 Petrikovsky BM: First-trimester diagnosis of duodenal atresia. Am J Obstet Gynecol 1994; 171:569-570.

31 Krizko M Jr, Ferianec V: Prenatal diagnosis of genetic syndromes-imaging modalities; in Kralova E (ed): Education of Medical Staff in EU. Bratislava, Asklepios, 2007, p 26.

32 Paldia R, Gubza S, Scholtz E, Ferianec V: Development of sonography since 1980 . Prakt Gynekol 1995;2:209.

33 Hlinka D, Dudas M, Herman M, Kalina I: Experimental attempts to extend the current preimplantation genetic diagnosis with individual karyotypization of human blastomeres. Reprod Nutr Dev 2001;41:91-106.

34 Bhushan A, Itoh N, Kato S, Thiery JP, Czernichow P, Bellusci S, Scharfmann R: Fgf10 is essential for maintaining the proliferative capacity of epithelial progenitor cells during early pancreatic organogenesis. Development 2001;128:5109-5117.
35 Hebrok M, Kim SK, St Jacques B, McMahon AP, Melton DA: Regulation of pancreas development by hedgehog signaling. Development 2000;127:4905-4913.

36 Ramalho-Santos M, Melton DA, McMahon AP: Hedgehog signals regulate multiple aspects of gastrointestinal development. Development 2000;127:2763-2772.

37 Dudas M, Kaartinen V: TGF-beta superfamily. Curr Top Dev Biol 2005;66:65-133.

- 38 Kamisawa T, Tu Y, Egawa N, Tsuruta K, Okamoto A, Kamata N: MRCP of congenital pancreaticobiliary malformation. Abdom Imaging 2007;32:129-133.

-39 Mortele KJ, Rocha TC, Streeter JL, Taylor AJ: Multimodality imaging of pancreatic and biliary congenital anomalies. Radiographics 2006;26:715-731.

-40 Ueki T, Yao T, Beppu T, Otani K, Yorioka M, Sakaguchi S, Matsui T, Ono H, Nakamura H: Three-dimensional computed tomography pancreatography of an annular pancreas with special reference to embryogenesis. Pancreas 2006;32:426-429.

-41 Nijs E, Callahan MJ, Taylor GA: Disorders of the pediatric pancreas: imaging features. Pediatr Radiol 2005;35:358-373.

42 Jayaraman MV, Mayo-Smith WW, Movson JS, Dupuy DE, Wallach MT: CT of the duodenum: an overlooked segment gets its due. Radiographics 2001;21: S147-S160.

43 Norton KI, Tenreiro R, Rabinowitz JG: Sonographic demonstration of annular pancreas and a distal duodenal diaphragm in a newborn. Pediatr Radiol 1992;22:66-67.

44 Iuchtman M, Golan Y, Heldenberg D, Kessler FB: Situs inversus abdominis in association with duodenal obstruction and internal hernia. Am J Perinatol 1993;10:255-257.

-45 Bailey PV, Tracy TF Jr, Connors RH, Mooney DP, Lewis JE, Weber TR: Congenital duodenal obstruction: a 32-year review. J Pediatr Surg 1993;28:92-95.

46 Akel S, Halabi J, Shawis R: Abdominal situs inversus with congenital duodenal stenosis: rare association. Eur J Pediatr Surg 1998;8: 55-57.

47 Tovar JA, Benavent M, Bachiller C, DiezPardo JA: Preduodenal portal vein (in Spanish). An Esp Pediatr 1978;11:565-574.

48 Barrack SM, Kyambi JM, Ndungu J, Wachira $\mathrm{N}$, Anangwe G, Safwat S: Intestinal atresia and stenosis as seen and treated at Kenyatta National Hospital, Nairobi. East Afr Med J 1993;70:558-564

49 Falade AG, Shonubi AM: Pattern of congenital alimentary tract malformation in Ibadan, Nigeria. East Afr Med J 1997;74:385-388.

50 Dalla Vecchia LK, Grosfeld JL, West KW, Rescorla FJ, Scherer LR, Engum SA: Intestinal atresia and stenosis: a 25-year experience with 277 cases. Arch Surg 1998;133:490496.

-51 Jotz GP, Carnevale FC, Onofrio PL, Chaib E, Mello JB: Annular pancreas. Report of a case and review of the literature (in Portuguese). Arq Gastroenterol 1996;33:29-31. 
-52 Merrill JR, Raffensperger JG: Pediatric annular pancreas: twenty years' experience. J Pediatr Surg 1976;11:921-925.

53 Jimenez JC, Emil S, Podnos Y, Nguyen N: Annular pancreas in children: a recent decade's experience. J Pediatr Surg 2004;39: 1654-1657.

54 Sencan A, Mir E, Gunsar C, Akcora B: Symptomatic annular pancreas in newborns. Med Sci Monit 2002;8:CR434-CR437.

55 Kallen B, Mastroiacovo P, Robert E: Major congenital malformations in Down syndrome. Am J Med Genet 1996;65:160-166.

56 Stanley P, Law BS, Young LW: Down's syndrome, duodenal stenosis/annular pancreas, and a stack of coins. Am J Dis Child 1988; 142:459-460.
57 Baumgartner F, Moore TC: Atretic, obstructive proximal duodenal mass associated with annular pancreas and malrotation in a newborn male. Eur J Pediatr Surg 1992;2:42-44.

58 Adeyemi SD: Combination of annular pancreas and partial situs inversus: a multiple organ malrotation syndrome associated with duodenal obstruction. J Pediatr Surg 1988; 23:188-191.

59 Ruben GD, Templeton JM Jr, Ziegler MM: Situs inversus: the complex inducing neonatal intestinal obstruction. J Pediatr Surg 1983; 18:751-756.

60 Maier M, Wiesner W, Mengiardi B: Annular pancreas and agenesis of the dorsal pancreas in a patient with polysplenia syndrome. AJR Am J Roentgenol 2007;188:W150-W153.
61 Savino A, Rollo V, Chiarelli F: Congenital duodenal stenosis and annular pancreas: a delayed diagnosis in an adolescent patient with Down syndrome. Eur J Pediatr 2007; 166:379-380.

62 Mitchell J, Punthakee Z, Lo B, Bernard C, Chong K, Newman C, Cartier L, Desilets V, Cutz E, Hansen IL, Riley P, Polychronakos C: Neonatal diabetes, with hypoplastic pancreas, intestinal atresia and gall bladder hypoplasia: search for the aetiology of a new autosomal recessive syndrome. Diabetologia 2004;47:2160-2167. 